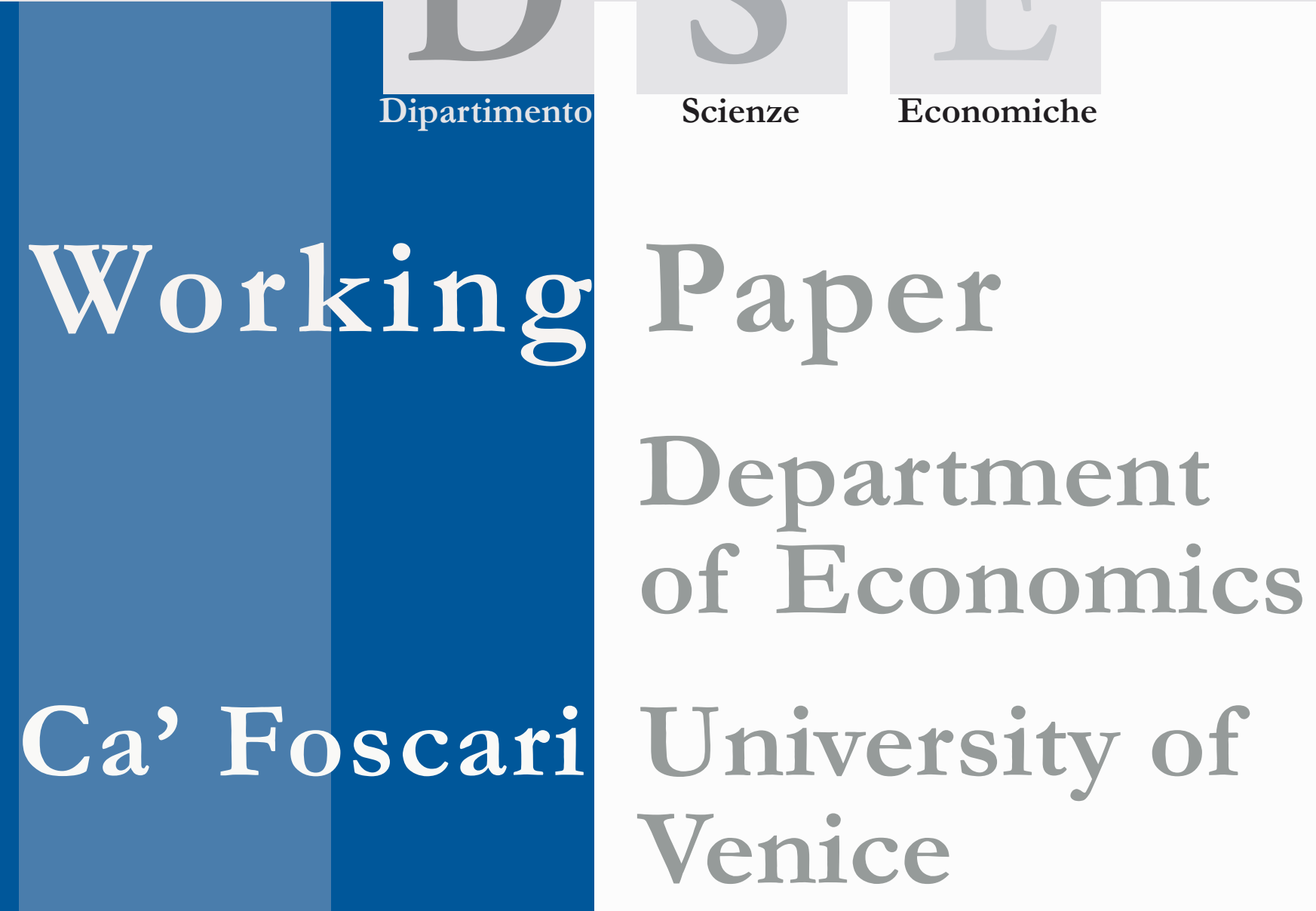

Tito Boeri

Agar Brugiavini

Pension Reforms and Women Retirement Plans 


\title{
Pension Reforms and Women Retirement Plans
}

\author{
Tito Boeri \\ Bocconi University, Milan \\ Agar Brugiavini \\ Ca' Foscari University of Venice and SSAV
}

First Draft: 31 October 2008

\begin{abstract}
We analyse the effects of pension reforms on the planned retirement age of women by exploiting within country variation in pension wealth across cohorts of workers in Italy after the Amato and Dini reforms of the early 1990s, which introduced a "Notionally Defined Contribution" (NDC) method for calculating pension benefits. The effect of the change in the pension regime on retirement decisions is affected by the presence of gaps in careers of women. Binding constraints related to eligibility to pensions indeed reduce the responsiveness of women to changes in pension rules. This explains why, contrary to a priori expectations, men are often found to be more reactive than women to changes in pension rules.
\end{abstract}

\section{Keywords}

Pensions, Social Security Wealth and Accrual, Gaps in careers

\section{JEL Codes}

J14, J16, J26

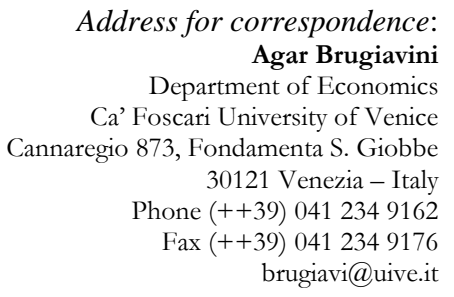

This Working Paper is published under the auspices of the Department of Economics of the Ca' Foscari University of Venice. Opinions expressed herein are those of the authors and not those of the Department. The Working Paper series is designed to divulge preliminary or incomplete work, circulated to favour discussion and comments. Citation of this paper should consider its provisional character. 


\section{Introduction $^{1}$}

The determinants of female labour force participation decisions have been thoroughly investigated both in theory and in empirical work. Although gender differences are stressed in analyzing responses to reforms or simulated reforms of pensions (see for example Gruber and Wise 2004), rather little is known about the interactions between generosity of pension systems and labour supply decisions of women. This is quite unfortunate as women' labour supply is likely to exhibit a different responsiveness than labour supply of men to changes in the internal rates of returns of pension systems (Disney, 2004).

On the one hand, the income and wage elasticities of labour supply are generally found to be higher for women than for men due to differences in preferences, intra-family bargaining and productivity in home production. Moreover, women have longer life expectancies than men, hence they are more likely to experience large variations in lifetime incomes when there are changes in rules concerning their own pensions, widower pensions and retirement provisions for their husbands. This suggests that women labour supply should be more responsive to changes in pension rules than labour supply of men.

On the other hand, gender differences in working-careers and in the role of women within the family are likely to reduce the responsiveness of labour supply of women to changes in retirement rules. Because of frequent breaks in career, women usually end up with less pension rights and then retirement income than men. This implies that in some cases women, after a given age, cannot even "catch up" when it comes to pensions as they do not have enough paid working years (Clare 2004). Thus, although unconstrained choices of women would involve a stronger responsiveness to the incentives embedded in pension systems, their choices are actually constrained by career gaps and minimum contribution requirements.

A promising strand of research has started looking at the risk-return implications of gender differences in the age profile of labour income and its implications for resources in retirement (Baxter, 2001). A crucial role in determining expected social security benefits is

\footnotetext{
${ }^{1}$ We wish to thank Tullio Jappelli, two anonymous referees and participants to the workshop on "Labour Marker and Social Security Reforms"(Tilburg, 2005) for useful comments on an initial draft. Unflagging statistical assistance by Simona Baldi and Lisa Callegaro is also gratefully acknowledged.
} 
played by the stochastic features of the earnings profile, particularly by gaps in the career of women. A preliminary conclusion is that women should adopt a different strategy than men in accumulating resources for retirement.

The purpose of this paper is to contribute to this literature by exploiting within country variation in pension wealth of women in Italy after the Amato and Dini reforms of the early 1990s. The latter reform introduced a "Notionally Defined Contribution" (NDC) method for calculating pension benefits, tightly (and transparently) linking pension claims to the accrued contributions of the worker. The NDC system mimics a capitalized pension scheme, with a significantly lower tax component than the previous Defined-Benefits (DB) system. Thus, comparing participation decisions for women vis-a-vis men before and after the reforms can offer valuable insights as to the effects of pension rules on women on the retirement decision.

We draw on data from the Bank of Italy Survey on Household Income and Wealth (SHIW), which is a large cross-sectional sample carried out every two years and it records several features of the individuals' socio-economic situation. We also draw on the Italian quarterly Labour Force Survey (LFS) to track the development of new contractual types in Italy and gender differences in career paths. We show that women typically exit the labour market earlier than men. Although health conditions and household arrangements may also affect the timing of retirement, consistently with previous work (Gruber and Wise, 1999; Brugiavini and Peracchi, 2004) we argue that eligibility rules and economic incentives embedded in social security systems are indeed a main determinant of the timing of exit from the labour force. We model changes in the planned retirement age and we find that workers are affected in their retirement choice by their expectations about future social security arrangements and by the accrued value of their social security (pension) benefits. The decision on the timing of retirement of women at older ages is found to be more sensitive to pension reforms than that of men. In particular, women tend to have a larger number of gap-years and their career and this is found to positively affect the delay in the planned retirement age.

The plan of the paper is as follows. Section one documents the variability in attachment to the labour market at older ages for Italian men and women. Section two provides a simple framework for empirical analysis of retirement and entry decisions of women under different pension rules. Section three dwells on retirement decisions. Finally, section four summarizes the main findings and provides suggestions for further research.

\section{Social Security Reforms and Working Lives}

In order to analyse the effect o pension reforms on the retirement decision of women it is important to first briefly describe pension reforms and then provide some preliminary evidence of the labour market behaviour of women and men in Italy.

Pension systems differ both in the design of pension benefits and in eligibility rules. In most European countries benefits are computed according to a defined benefit (DB) method, where benefits are related to some average of lifetime earnings. A final salary computation method relates benefit to the last wage: this was basically adopted in Italy until the 1992 pension reform as well as during the transitional phase which Italy is currently experiencing. In particular, until 1992 the pension benefit was based on the average of the last five years earnings, while during the transitional phase these became the last 10 years earnings (see 
Table A1 for details). The 1995 Pension reform changed radically this system as benefits should now be computed according to a Notionally Defined Contribution (NDC) method. In the latter case, pension benefits are automatically linked to an average of lifetime earnings, adjusted by some actuarial coefficients.

While the recent reform of the Italian pension system (the 1995 reform) is normally regarded as a move towards a more actuarially fair system, because it links benefits to the value of lifetime contributions, it is still debated who might gain or lose from such a change. In particular, it is not clear how workers with gaps in their careers would fare under the new regime as very little is known about the length of working life and how recent trends of shorter working careers are impacting on pension provisions (see also Brugiavini and Peracchi 2004).

In order to provide some preliminary evidence in this respect, we investigated the SHIW sample for the 2002 wave, and, whenever appropriate, for previous waves. The SHIW sample is a large representative sample of Italian households, collected every two years (see Appendix 2 for a description of the SHIW data).

\subsection{Gaps in careers}

The first relevant feature distinguishing the working career of women is the existence of gaps. These could be due to absence from work for maternity leave or for other reasons, including unemployment spells. Whatever the reason, even in the lucky case in which the absence from work is "covered" in terms of social security, both because the women gets a benefit and she gets some imputed contributions, the woman would lose in terms of wage-growth due to reduced productivity growth (see Olivetti, 2006) and to the loss of tenure-related wage growth. In order to document these features of the Italian labour market we present simple statistics on the number of gap-years for men and women: in our sample we can actually measure gap-years in which no social security contribution was paid for the worker.

The average number of "gap-years" in the working careers of individuals is obtained in our sample through a simple "imputation" method, by distinguishing retirees from workers. In fact, for the former group we make use of retrospective information on three items:

- the age that the respondent reported as the date of entry in the labour market;

- the self-reported age of retirement;

- the self-reported number of years of contributions.

From this information, we can compute the difference between years in which the retiree was potentially active and years when she was out of the labour force. This is a noisy measure both because the respondent can have a vague recollection (especially if far in the past) of the events and because the number of years of contributions may not coincide with the "gapyears". However, for the purpose of this paper it is not relevant to look at the actual level of the number of gap-years, but rather to make a comparison between men and women of different age groups. We distinguish also educational attainments (low education is no education or primary, medium is lower secondary and upper secondary, high is college and above). Obviously the bulk of the distribution for these people is for the ages 55 to 85 .

Table 1 shows the average number of "gap-years" for retired individuals distinguishing also educational levels: for retirees, women have a systematically higher number of years "lost". However, at lower educational attainments the difference between men and women is not so sharp. 
Table 1

Average number of gap years per retired individual by educational attainment

\begin{tabular}{|c|c|c|c|c|c|c|}
\hline \multirow{3}{*}{$\begin{array}{l}\text { education } \\
\text { Age }\end{array}$} & \multicolumn{3}{|c|}{ Men } & \multicolumn{3}{|c|}{ Women } \\
\hline & low & medium & High & Low & medium & high \\
\hline & & & & & & \\
\hline$<50$ & 1.35 & 0.38 & 0 & 1.87 & 1.43 & 1.36 \\
\hline 50-55 & 2.61 & 1.34 & 0 & 3.38 & 2.02 & 0.89 \\
\hline $56-60$ & 3.87 & 2.01 & 0.6 & 10.8 & 5.44 & 0.79 \\
\hline 61-65 & 7.72 & 3.16 & 1.51 & 13.19 & 8.11 & 0.79 \\
\hline $66-70$ & 9.79 & 5.74 & 1.34 & 13.57 & 7.25 & 2.36 \\
\hline 71-75 & 11.05 & 5.56 & 1.95 & 13.31 & 7.11 & 3.33 \\
\hline$>75$ & 11.67 & 6.21 & 2.07 & 14.55 & 7.47 & 2.25 \\
\hline
\end{tabular}

Source: own calculations on the SHIW data- 1989-2002 waves

In order to complete the analysis, we provide the same estimate for persons who are still working, hence accruing pension rights. These observations are right-censored as far as potential labour market experience and years of contributions are concerned.

Figure 1

Distribution of the Years of Contributions for Working Men and Women

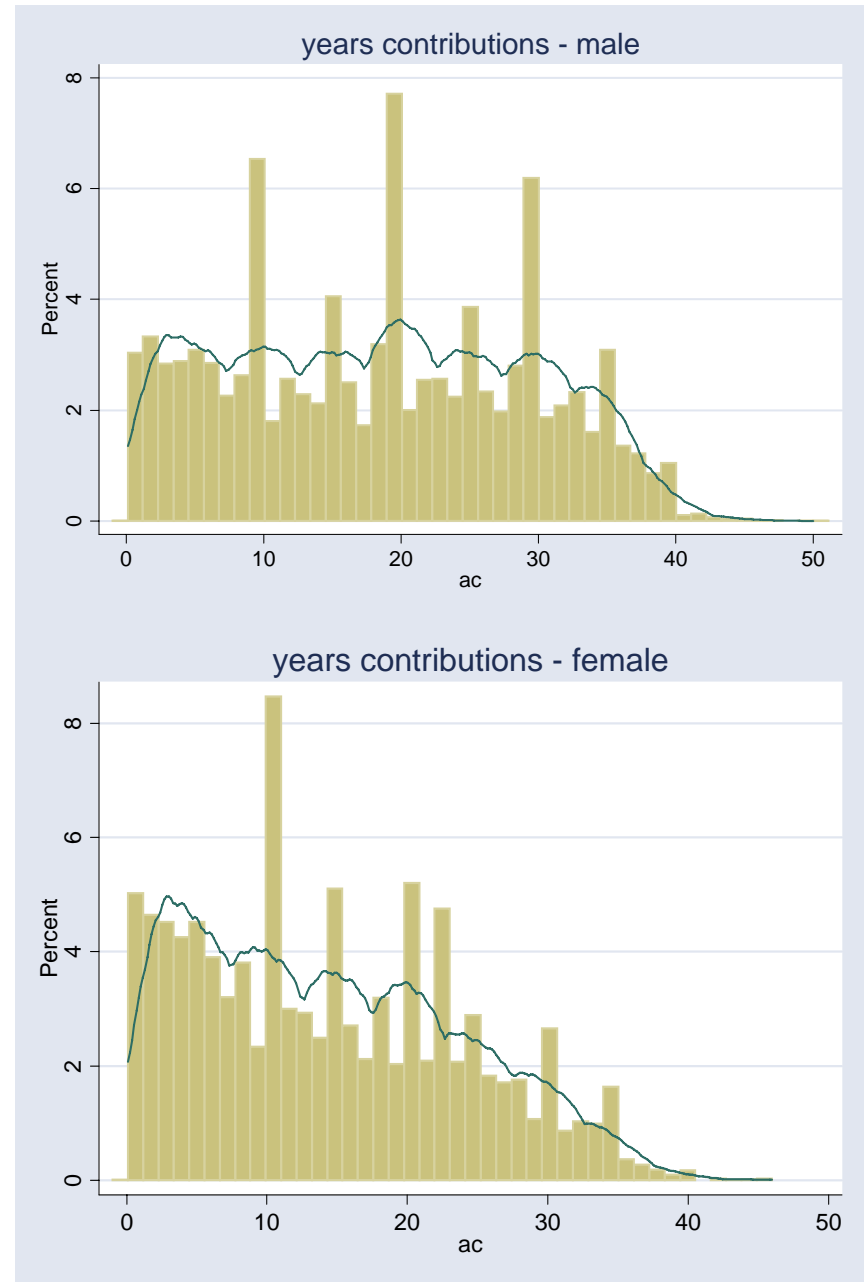

Source: Own calculation on the SHIW Survey, 1989-2002 


\section{Figure 2}

\section{Gap-Years in Working Careers for Men and Women}
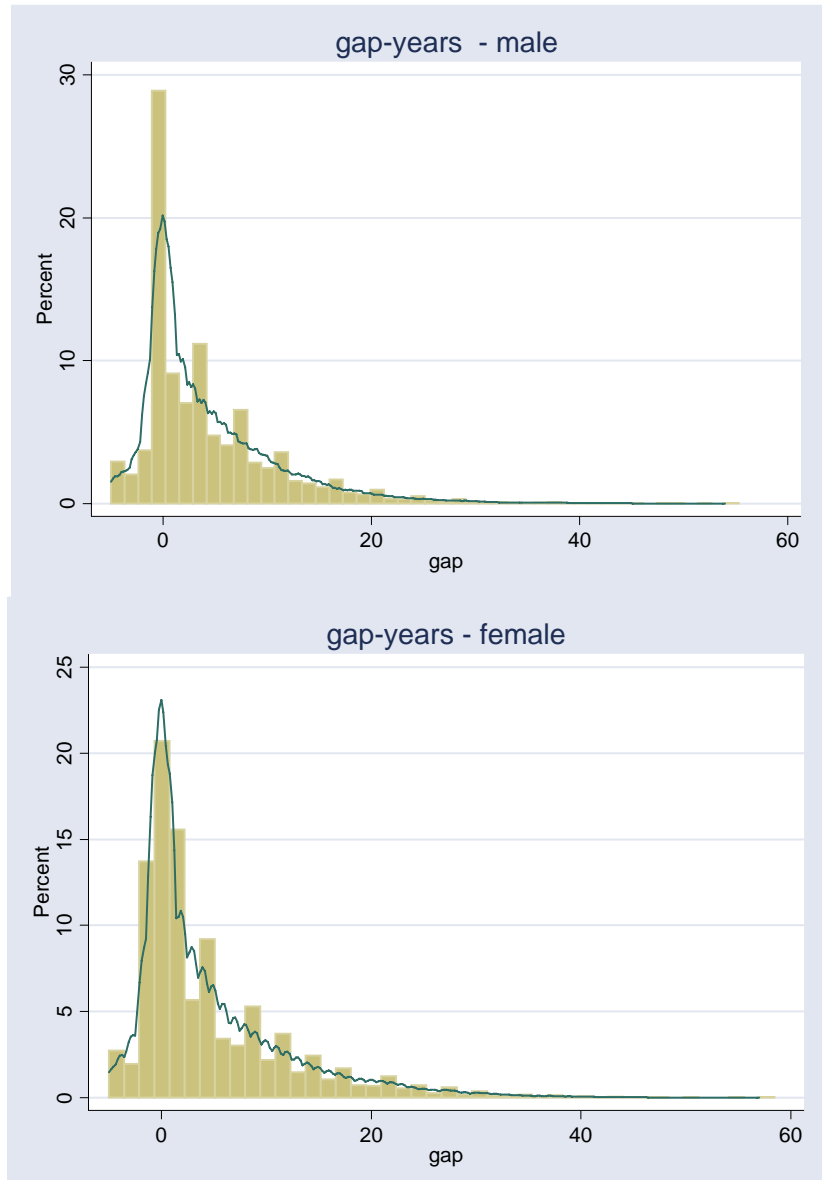

Source: Own calculation on the SHIW Survey, 1989-2002

Figures 1 and 2 show the percentage distribution (with a kernel density estimator) of contributions and gap-years of men and women. Negative gap years can be related to decisions to "buy back" years of study, earlier (than imputed) entry in the labour market as well as recall bias. Women contributions are more concentrated at the lower end and also the percentage of gap-years is more concentrated on the positive values.

The mean number of contribution years is 18.56 for men and 15.41 for women (median 19 and 15), the bottom $25 \%$ of the distribution has 10 years for men and 7 years for women. As for the gap-years, the mean is 4 for men and 4.45 for women (conditional on having at least a gap year), at the top of the distribution ( $90 \%$ percentile) the number of gap-years is 10 for men and 14 for women (also conditional on having at least one gap-year).

The breakdown of gap years by cohort and sector confirms that gap-years are higher for female workers, and years of contributions are lower, on average, for women than for men. Gap-years are also higher for the self-employed than for the employees; however this pattern does not seem to be affected by gender-composition.

It should be stressed that breaks in career are becoming even more frequent, notably for women, after the labour market reforms of the 1990s which expanded the scope of fixed-term 
contracts. As shown by Figure 3, which is based on April-to-April labour market transitions as estimated on the basis of the Italian Labour Force Survey, fixed-term contracts became recently the main port of entry into the labour market for women, much more than in the case of men. Temporary employment is subject to a risk of job loss which is up to 10 times higher than in open-ended contracts.

Figure 3

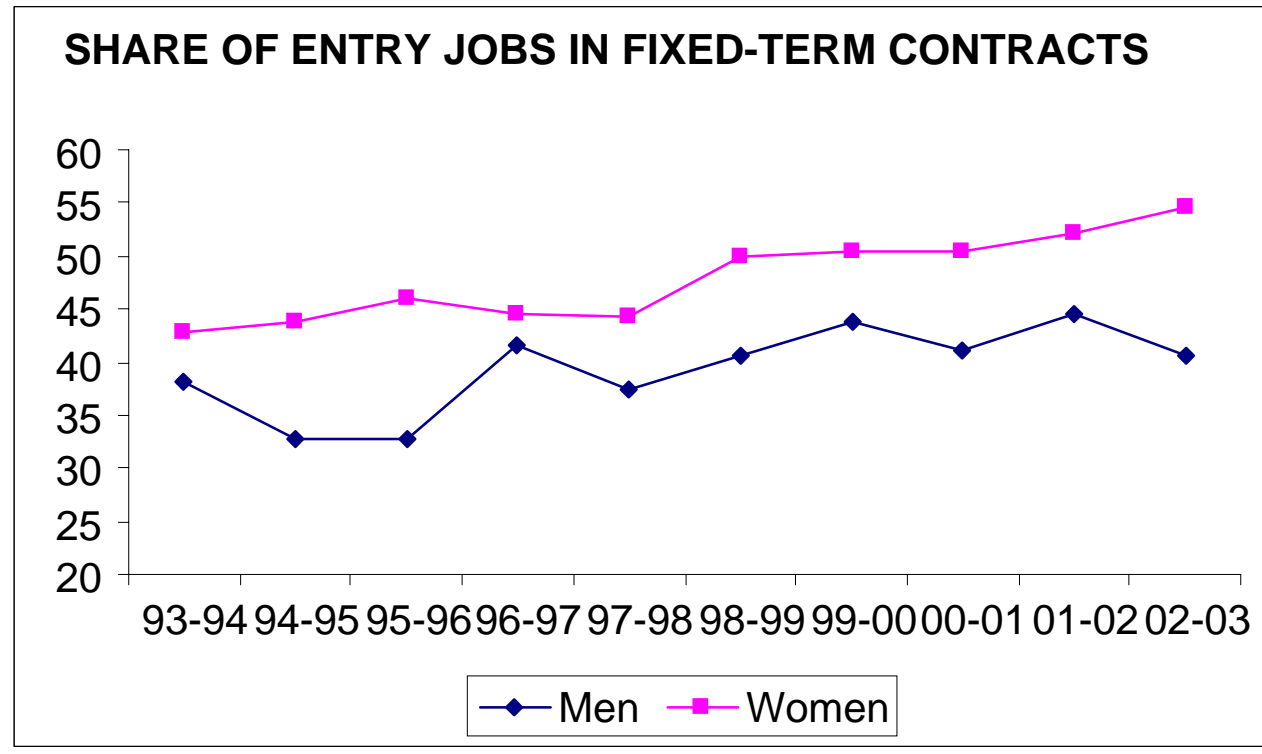

Source: Italian labour Force Survey, several years

Overall this preliminary evidence shows that gaps in careers are particularly important for women. In the next sections we will evaluate how this lack of contributions affects social security wealth and constrains retirement plans of women.

\section{An empirical framework}

In order to link the evidence provided in Section 1 to the valuation of social security benefits, it is important to provide a framework relating the working life of individuals to their planned retirement age.

Retirement decisions are the result of a complex lifetime decision model. In fact these decisions interact with consumption-saving decisions and with other insurance decisions, such as medical insurance (see Gustman and Steinmeier, 1994, Gruber, 1998). In this paper we focus on the decision to retire and abstract from private saving decisions (taken as given). Furthermore, for Italian workers we can safely assume that medical insurances are in place which do not require to fully investigate the interaction with health risks, at least not differentially across genders.

Although in this paper the focus is on the "planned retirement age" rather than on actual retirement, the natural framework is within the "option value" model introduced by Stock and Wise (1990). We do not model the actual sensitivity to the option value, but since the planned retirement age embeds expectations about the future value of social security claims, we borrow from the option value literature some of its basic measures. In fact, the key feature of the model is that, when deciding on whether or not to retire today, a worker compares the 
expected value of retiring immediately with the expected value of continuing to work and postponing retirement, which is a once and for all, irreversible decision.

The crucial variable in this setup is the social security wealth (SSW). For a worker of age $a$, in case of retirement at age $h \geq a$, this is defined as the expected present value of future pension benefits (see Appendix 3 for details)

$$
S S W_{h}=\sum_{s=h+1}^{S} \rho_{s} B_{s}(h)
$$

Here $S$ is the age of certain death, $\rho_{s}=\beta^{s-a} \pi_{s}$, with $\beta$ denoting the pure time discount factor and $\pi_{s}$ the conditional survival probability at age $s$ for an individual alive at age $a$, and $B_{s}(h)$ the pension flows expected from age $s \geq h+1$ onwards in case of retirement at age $h$.

Social security wealth is a static stock measure, a "sufficient statistic" for the entire social security benefit stream, including eligibility rules and benefit computation rules. The decision to retire is intrinsically dynamic. In this case the individual takes into account the value of future human capital (for given wage) and the social security rules in place. In two contributions Gruber and Wise (1999 and 2004) have suggested a framework to implement a tractable version of the option value model. This is focused on the role of incentives at the individual level and requires micro data for workers observed at different ages. In this paper we draw heavily on this method, as implemented by Brugiavini and Peracchi (2004).

In what follows we only present, after a brief introduction of the retirement decision model, the key variables which are going to be used in this paper.

Consider a worker of age $\boldsymbol{a}$, who decides to work until age $\boldsymbol{r}>\boldsymbol{a}$, expects to earn $\boldsymbol{W} \boldsymbol{s}$ in each year $\boldsymbol{s}$ until retirement and then to receive a pension equal to $\boldsymbol{B}_{r}(\boldsymbol{s})$ until the age of death $\boldsymbol{S}$. The pension benefit depends on the retirement age $\boldsymbol{r}$, on past work history and on the pension rules. To simplify algebra (without unduly forcing reality) it is also assumed that hours of work before retirement are exogenous (they are related to events, like job loss, which are outside the choice set of individuals), and that after retirement the individual does not work at all. Thus, when deciding on whether or not to retire at age $\boldsymbol{r}$, the worker evaluates the indirect utility of the stream of future income as follows

$$
V_{a}(r)=\sum_{s=a}^{r-1} \beta^{s-a} U_{1}\left(W_{s}\right)+\sum_{s=r}^{S} \beta^{s-a} U_{2}\left(B_{s}(r)\right)
$$

where $\beta$ is the discount factor, $\mathbf{U}_{\mathbf{1}}(\mathbf{W})$ is the indirect utility of future earnings and $\mathbf{U}_{\mathbf{2}}(\mathbf{B})$ is the indirect utility of future pension benefits. Evaluated at age $\boldsymbol{a}$, the gain of postponing retirement until age $\boldsymbol{r}>\boldsymbol{a}$ is given by

$$
G_{a}(r)=E_{a}\left[V_{a}(r)\right]-E_{a}\left[V_{a}(a)\right]
$$

where $\boldsymbol{E}_{\boldsymbol{a}}$ denotes the expectation operator based on the information available up to age $\boldsymbol{a}$. .

The probability that a worker retires at age $\boldsymbol{a}$ is therefore 


$$
\boldsymbol{P}(\boldsymbol{a})=\operatorname{Pr}\left\{\boldsymbol{G}_{\boldsymbol{a}}\left(\boldsymbol{r}^{*}\right) \leq 0\right\}
$$

where $\boldsymbol{r}^{*}=\operatorname{argmax}_{\boldsymbol{r}} \boldsymbol{G}_{\boldsymbol{a}}(\boldsymbol{r})$ subject to $\mathrm{T}_{\mathrm{m}} \geq \mathrm{r} \geq \alpha$ is the age at which the gain of postponing retirement is highest. As retirement is irreversible and there is uncertainty about future earnings and pension benefits, there is an option value of waiting given by

$$
E_{a}\left[V_{a}\left(r^{*}\right)\right]-E_{a}\left[V_{a}(a)\right]
$$

The empirical implementations of this model does not need to fully work out the option value. A valid proxy for this measure is an incentive variable, like the Peak Value (PV). At age $a$ :

$$
P V_{a}=\max _{h}\left(S S W_{h}-S S W_{a}\right), \quad h=a+1, . ., R,
$$

where $R$ is the mandatory retirement age (the latter does not exist in Italy, but given that everyone is retired by age 65 , we find it reasonable to put $R=70$ ). Thus, the peak value is the maximum difference in SSW between retiring at future ages and retiring at the current age.

Having provided the definition of social security wealth and of its dynamic versions we can now briefly discuss why these are useful concepts in our paper. First, we look at the actual retirement status in the cross-sectional sample, then we move on to describe the expectations about retirement age in a "natural experiment" framework.

\subsection{Retirement decisions}

Social security wealth plays essentially a twofold role in the decision as to whether to retire or continue working. The first role is through its traditional wealth and substitution effects: higher social security wealth (SSW) induces individuals to consume more of all goods, including leisure (assumed to be a normal good), and to retire earlier, counteracting the pure substitution effect that operates in the opposite direction. The second role is more intrinsically dynamic and, as discussed in the previous section, can be captured by its peak value: the individual's decision to continue to work is a function of the increase in retirement consumption resulting from additional work.

A typical retirement model would therefore use both Social Security Wealth (SSW) and an incentive variable (e.g. the peak value) in a regression of the planned (or actual) retirement age $\left(\mathbf{R}_{\mathbf{i t}}\right)$ :

$$
R_{i t}=b_{0}+b_{1} S S W_{i t}+b_{2} P e a k_{i t}+b_{3} X_{i t}+b_{4} A G E_{i t}+. .+e_{i t}
$$

In particular, SSW is the expected present discounted value of social security benefits that is available to the person $\boldsymbol{i}$ if she retires that year $(\boldsymbol{t})$; Peak is the incentive measure defined by equation (5); $\mathbf{X}$ is a vector of control variables that may importantly influence the retirement decision but do not enter directly into the calculation of SSW (e.g., education, region of residence, industry dummies, occupation dummies, marital status); AGE is the age of the worker. When the dependent variable is dichotomous, the model is normally estimated as a probit. As we shall treat the retirement age as a continuous variable, we will instead rely on a simple linear model. 
In our data we do not have enough transitions from work to retirement and cannot model actual current decisions to retire as optimal responses to social security reforms, also because this would require following the panel observations for a long period of time. However the SHIW sample contains a specific question on the planned retirement age which is asked to all workers. Hence we model changes in planned retirement age (see also Bottazzi, Jappelli e Padula 2006). This requires that the worker forms expectations on her future social security wealth and decides her retirement age on the basis of knowledge of both, eligibility rules and the maximum "value" of retirement. What is relevant for us is not just the change in social security wealth between today and tomorrow, based on the idea that the worker who is "at risk" of retirement evaluates today whether to work en extra year, but rather the expected change in the maximum social security wealth at the first future eligibility age, discounted at the current age.

As individuals change their planned retirement ages (say they plan to work more and plan to postpone retirement) their future path of social security benefits should also be changed. We refer to the present discounted value of future social security wealth corresponding to a future age, which is also chosen as a retirement age, as the "subjective peak value" for the worker. Note that this might not always correspond to the actual maximum social security wealth ("objective peak value") for the entire age profile of the individual ${ }^{2}$.

As it will become clear in the actual application, we exploit the panel nature of the data only as a rotating panel and in this sense it is reasonable to assume that the future optimal retirement age is a "moving target" and not a once-for-all decision. This is also the intuition behind the option-value model of retirement which, in the reduced form adopted in this paper, allows for re-planning at each age.

We make use of this particular incentive variable $\left(\mathrm{DSSP}=\right.$ Peak Value $\mathrm{t}_{+1}$-Peak Value ${ }_{t}$ ) in a standard linear regression where we take a "natural experiment approach". In particular the dependent variable is the difference in the planned retirement age between each wave post 1995 in 1995. This is related to the change in the Peak Value between each year post 1995 and the Peak Value in 1995, plus other explanatory variables including the number of gapyears. It should be noted that the change in the incentive variable is only due to regulatory changes exogenous to the individual, as it will be clear in Section 2.2 below $^{3}$. We focus on a simple linear model in order to stress the "natural experiment" interpretation of the regression framework.

$$
\Delta R_{i t}=b_{0}+b_{1} \Delta \text { Peak }_{i t}+b_{2} X_{i t}+b_{3} A G E_{i t}+. .+e_{i t}
$$

Because changes in SSW are usually quite small and take place gradually, one can hardly obtain sensitivity of actual choices to the social security wealth variable. However, thanks to the recent pension reforms in Italy, we are in a position to include in our estimates discrete changes in the Peak Value. Moreover, these changes have been particularly relevant from some groups in the population (see Attanasio and Brugiavini, 2003), especially those "middle aged" workers who had been treated generously before 1995 .

\footnotetext{
${ }^{2}$ See Gruber and Wise 1999 for a formal definition of "peak values". The peak value is a global maximum, while we take local maxima, each corresponding to a future retirement age.

${ }^{3}$ Regressions based on a probit specification are consistent with the results displayed below and available upon request.
} 
It is well known that women in Italy (particularly in the public sector) had an advantage over men as they could retire very early without any actuarial penalty. The 1995 reform levelled off these differences. Hence, the differential impact of this reform should allow us to better capture empirically the response in terms of labour supply. Before turning to that, we need to characterise the reduction in the level of SSW associated with the 1995 reform.

\subsection{Assessing Social Security Wealth under different Pension Regimes}

In this Section we document how changes in pension regimes have affected social security wealth of men and women. The effects depend crucially on the earnings profiles of individuals and on the following three elements:

(a) cohort differences;

(b) variability in educational levels, and

(c) variability in the length of working careers (and gaps in careers).

As we wish to capture as much as possible these variations, we cannot rely on mean or median earnings profiles. The SHIW sample has several advantages in this respect. Firstly, it is a large cross-sectional sample and covers several years (1978 to 2002), though it has been run every two years. Secondly, it records current occupation as well as past occupation: a large fraction of workers in Italy, particularly women, is either employed in the public sector or is engaged in self-employment activities and it is important to take account of sectoral variability in pension arrangements because workers in different sectors historically have been treated differently by pensions regimes. Until 1995 there were up to 12 different public pension regimes in Italy. Thirdly, SHIW has a small panel component (rotating panel) that can be used to investigate actual transitions from work to retirement.

Table 2

Composition of the SHIW sample

\begin{tabular}{|l|c|c|c|c|c|}
\hline & $\mathbf{1 9 9 1}$ & $\mathbf{1 9 9 5}$ & $\mathbf{1 9 9 8}$ & $\mathbf{2 0 0 0}$ & $\mathbf{2 0 0 2}$ \\
\hline Men & & & & & \\
\hline Worker & $47 \%$ & $44 \%$ & $44 \%$ & $45 \%$ & $44 \%$ \\
\hline Retired & $17 \%$ & $20 \%$ & $19 \%$ & $22 \%$ & $25 \%$ \\
\hline Women & & & & & \\
\hline Worker & $24 \%$ & $25 \%$ & $26 \%$ & $26 \%$ & $27 \%$ \\
\hline Retired & $12 \%$ & $14 \%$ & $12 \%$ & $13 \%$ & $16 \%$ \\
\hline
\end{tabular}

Source: SHIW, several years

Table 2 provides the distribution of the SHIW data available for workers and retired individuals (we neglected other conditions such as disability or the fact of being housewives). Table 2 clearly shows that a larger percentage of individuals who are currently active or have been active in the past are men. This result is largely dominated by the labour market behaviour of older cohorts as there is a non negligible decline over time in the percentage of working men and an increase in the percentage of working women. 
We compute social security wealth (SSW) according to the expression given in (1). We implement two sets of rules: the pre-reform legislation (retributive system) and the postreform legislation (contributive system). In order to take account of exogenous variations only we apply the same eligibility rules to both regimes (the pre-reform eligibility) in such a way that the SSW reflects only exogenous changes in the benefit payments formula. In fact, the post-reform regime allows for a window of retirement ages between age 57 and age 65: eligibility would then be related to the generosity of the benefit itself. By fixing the eligibility rules of the pre-reform legislation we abstract from this problem.

Figure 4. Social security wealth under the pre-reform (retributive) and post-reform (contributive) rules by age. Men.

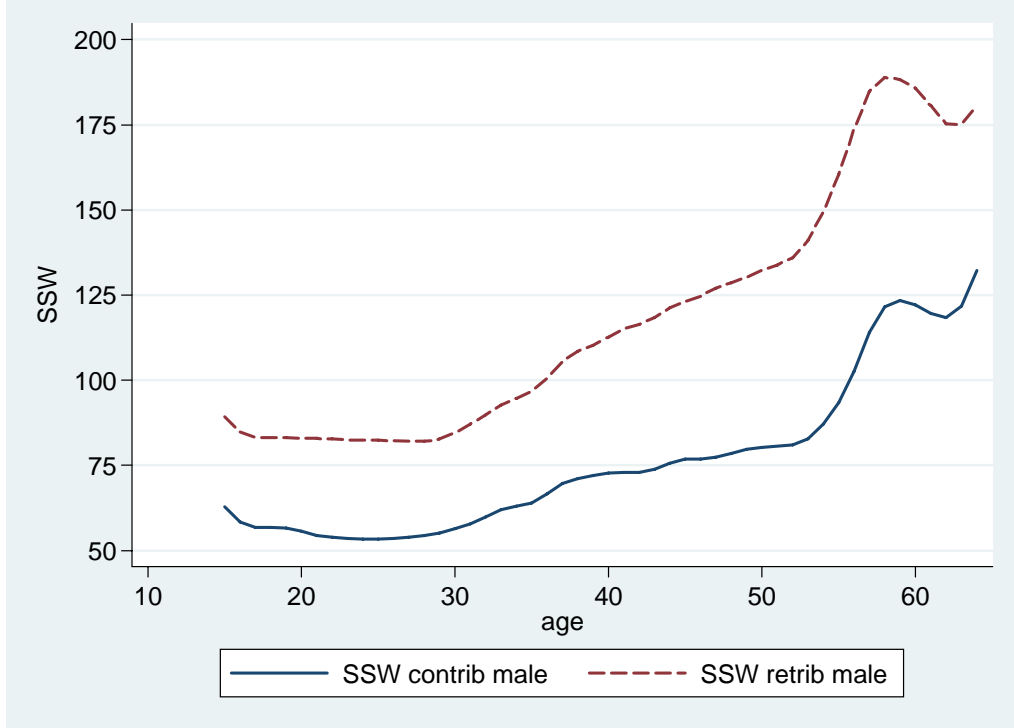

Figure 5. Social security wealth under the pre-reform (retributive) and post-reform (contributive) rules by age. Women.

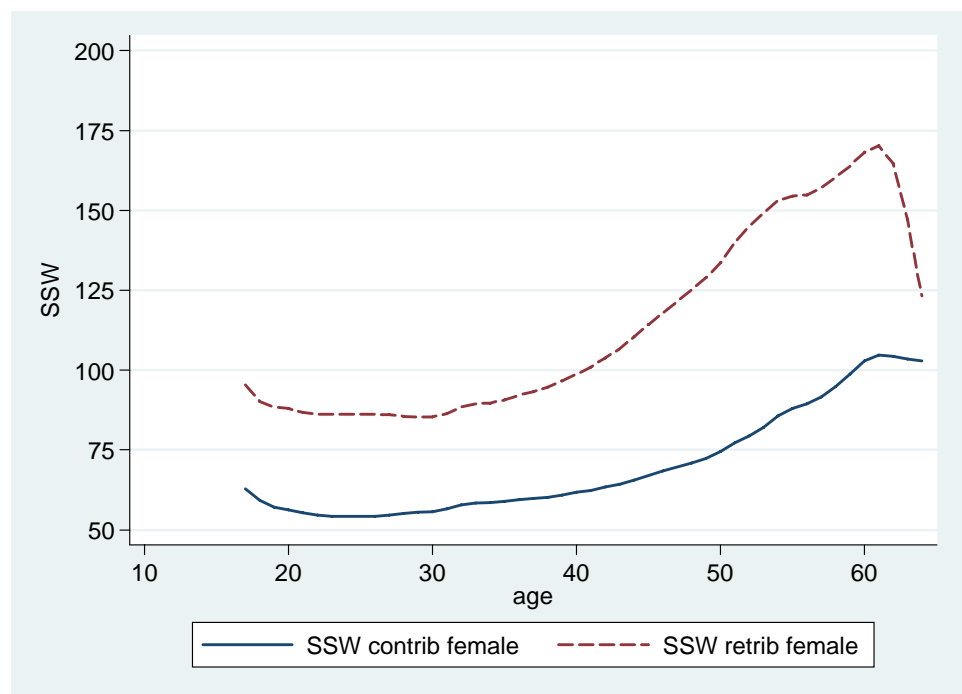




\section{Effects of Gap Years on the Retirement Decisions}

\subsection{Direct effect of gap years on the probability of being retired}

As documented above, women, notably retirees, have a significantly larger number of "gap years" than men. Before resorting to imputed social security wealth and accrual rates, we want to investigate the role of self-reported contribution years in a simple descriptive framework. In order to take this into account in our econometric analysis, we compute the ratio between self-reported years of contributions and potential labour market experience or the completed contributions (CC).

For retirees the denominator is the working life obtained as the difference between retirement age and the age of entry into the labour market, i.e., the complement to the "gaps in career". For workers, the potential labour market experience is given by the difference between the current age and the age at entry. The gender gap in the mean values of this index is selfevident in the case of retirees: 0,76 for women compared with 0,85 for men. Gender differences in $\mathrm{CC}$ among working (right-censored) individuals are much less marked ( 0,85 for women compared with 0,86 for men).

A simple probit analysis of the probability of being retired (1) or working (0) shows the effect of this index along with other socio-economic variables: in particular gender and education (Table 3).

Table 3 Probit analysis for actual retirement

\begin{tabular}{r|rrr}
\hline & Coef. & Std. Err. & \multicolumn{1}{c}{ Z } \\
age & .219306 & .0049885 & 43.96 \\
female & 1.828979 & .2394776 & 7.64 \\
married & .2836008 & .0695878 & 4.08 \\
medu & -.4062847 & .0574843 & -7.07 \\
hedu & -1.259138 & .1037002 & -12.14 \\
priv & .0071146 & .0620402 & 0.11 \\
self & -.8973826 & .0772006 & -11.62 \\
CC & $\mathbf{3 . 0 4 5 3 3 8}$ &. $\mathbf{2 1 8 3 7 8 9}$ & $\mathbf{1 3 . 9 5}$ \\
CC*gender & $\mathbf{1 . 7 2 6 0 7}$ &. $\mathbf{2 7 1 2 9 3 8}$ & $\mathbf{6 . 3 6}$ \\
const & -15.26231 & .4156669 & -36.72 \\
\hline Pseudo R2 & $=$ & & \\
\hline Number of obs & $=$ & & \\
\hline
\end{tabular}

The probit results suggest that the probability of being retired increases, as one would expect, with age. Women and people with low or no education are also more likely to be retired. Turning to the variables of interest: the higher the number of completed contributions years (CC) the higher is the probability of being retired, controlling for age, and this is more important for women than for men (CC interacted with gender, the latter taking value one in case of women). This may be because for many women additional years of contribution do not yield the seniority required for retirement. It should be stressed that current female workers are even more likely to be negatively affected by gaps in career due to the introduction of the NDC system. 
However, a number of caveats apply: first our evidence is entirely based on current and retrospective information, hence it does not exploit the forward-looking information contained in SHIW; secondly, it does not fully take into account the recent reforms, which have affected mostly younger workers (who clearly are not at risk of retirement).

\subsection{A Natural Experiment}

In order to capture the effects of the 1995 reform it is important to focus on younger cohorts, who are to a larger extent affected by the new rules ${ }^{4}$, described in the Appendix 1, which have clearly reduced the generosity of the public pension system. As discussed above, the SHIW sample contains (not for all years) questions on expectations concerning retirement. Workers are asked what is their planned retirement age and what is their expected replacement rate. Table 4 below displays mean values of these expectations for the waves reporting this information. We distinguish three relevant groups according to seniority: this is relevant to assess the extent to which a worker is "under the new regime" or not (see Appendix 1 for a description of the different pension regimes).

1) senior: workers with more than 18 years contributions in 1995, hence fully exempted from the Dini reform;

2) mid-senior: workers with less than 18 years contributions in 1995, who already worked in 1995, who moved only pro-quota to the new regime;

3) junior: people starting to work after1996, hence entirely under the new regime.

\footnotetext{
${ }^{4}$ The Italian social security system is currently going through a transitional period and the rules of the 1995 reform for benefit calculation are being applied "pro rata" according to the cohort of birth. The cohorts entering the labour market after 1996 will be completely under the new regime.
} 


\section{Table 4}

AVERAGE PLANNED RETIREMENT AGE, BY YEAR, SEX, SECTOR OF ACTIVITY AND SENIORITY

\begin{tabular}{llcc|ccccc|}
\multicolumn{8}{c}{ Men } \\
\hline \multicolumn{1}{c}{1989} & 1991 & 1993 & 1995 & 1998 & 2000 & 2002 \\
\hline private employees & Senior & $\mathbf{6 0 . 1 2}$ & $\mathbf{5 9 . 9 7}$ & $\mathbf{5 8 . 7 2}$ & $\mathbf{5 8 . 7}$ & $\mathbf{6 0 . 0 6}$ & $\mathbf{6 0 . 6 1}$ & $\mathbf{6 0 . 9 5}$ \\
& Mid & $\mathbf{6 0 . 0 6}$ & $\mathbf{6 0 . 8 6}$ & $\mathbf{6 0 . 5 2}$ & $\mathbf{6 1 . 4 4}$ & $\mathbf{6 2 . 0 4}$ & $\mathbf{6 2 . 4 1}$ & $\mathbf{6 2 . 8 7}$ \\
& Junior & - & - & - & - & $\mathbf{6 2 . 6 9}$ & $\mathbf{6 3 . 2}$ & $\mathbf{6 3 . 3 2}$ \\
\hline public employees & Senior & $\mathbf{6 0 . 3 4}$ & $\mathbf{6 0 . 5 9}$ & $\mathbf{5 9 . 6 1}$ & $\mathbf{5 9 . 5 4}$ & $\mathbf{6 0 . 4 3}$ & $\mathbf{6 1 . 1 5}$ & $\mathbf{6 1 . 0 9}$ \\
& Mid & $\mathbf{6 0 . 3 7}$ & $\mathbf{6 0 . 9 2}$ & $\mathbf{6 1 . 0 7}$ & $\mathbf{6 1 . 4 8}$ & $\mathbf{6 2 . 3 3}$ & $\mathbf{6 2 . 3 7}$ & $\mathbf{6 2 . 8 5}$ \\
& Junior & - & - & - & - & $\mathbf{6 3 . 0 9}$ & $\mathbf{6 3 . 9 3}$ & $\mathbf{6 3 . 9 6}$ \\
\hline self-employed & Senior & $\mathbf{6 2 . 2}$ & $\mathbf{6 2 . 4 6}$ & $\mathbf{6 2 . 1 3}$ & $\mathbf{6 0 . 5 8}$ & $\mathbf{6 3 . 6 2}$ & $\mathbf{6 3 . 6 1}$ & $\mathbf{6 3 . 7 2}$ \\
& Mid & $\mathbf{6 1 . 1 5}$ & $\mathbf{6 1 . 6 4}$ & $\mathbf{6 2 . 0 5}$ & $\mathbf{6 2 . 7}$ & $\mathbf{6 3 . 6 5}$ & $\mathbf{6 4 . 2}$ & $\mathbf{6 4 . 1 1}$ \\
& Junior & - & - & - & - & $\mathbf{6 4 . 2 8}$ & $\mathbf{6 4 . 5 1}$ & $\mathbf{6 4 . 7 8}$ \\
\hline
\end{tabular}

\begin{tabular}{|c|c|c|c|c|c|c|c|c|}
\hline \multicolumn{9}{|c|}{ Women } \\
\hline & & 1989 & 1991 & 1993 & 1995 & 1998 & 2000 & 2002 \\
\hline \multirow[t]{3}{*}{ private employees } & Senior & 56.82 & 56.88 & 56.53 & 57.37 & 58.83 & 59.36 & 59.36 \\
\hline & Mid & 56.84 & 57.83 & 57.35 & 58.84 & 59.52 & 60.11 & 60.51 \\
\hline & Junior & - & - & - & - & 60.33 & 61.02 & 61.21 \\
\hline \multirow[t]{3}{*}{ public employees } & Senior & 57.62 & 57.78 & 58.27 & 58.5 & 59.55 & 59.95 & 59.92 \\
\hline & Mid & 57.06 & 58.25 & 58.35 & 59.74 & 60.83 & 60.83 & 60.88 \\
\hline & Junior & - & - & - & - & 62.03 & 61.38 & 61.75 \\
\hline \multirow[t]{3}{*}{ self-employed } & Senior & 59.47 & 59.53 & 58.83 & 58.65 & 61.08 & 61.11 & 61.36 \\
\hline & Mid & 58.08 & 59.56 & 59.25 & 60.16 & 60.55 & 61.8 & 61.38 \\
\hline & Junior & - & - & - & - & 62.68 & 62.64 & 61.6 \\
\hline
\end{tabular}

There is a trend to report an increase in the retirement age and to expect lower replacement rates within each entitlement category and group of workers: an indication that workers are learning about the reform process (see also Jappelli, Padula and Bottazzi, 2003) ${ }^{5}$. Planned retirement age is higher for the self-employed. Junior workers have higher planned retirement ages as a direct effect of the reform (they have to fully incorporate the changes in their future plans).

We use these variables to test whether the 1995 reform has significantly affected the plans of individuals in our sample and particularly how relevant is the role played by the contribution history of women in affecting changes of these expectations after the reform. To this end, we make use of the rotating panel available in the SHIW (the same household is interviewed in 2 consecutive waves, see Appendix 2), which also displays the average planned retirement ages for this sample.

For the workers in our sample we can also estimate social security wealth (SSW) on the basis of projected lifetime earnings and given the legislation. Hence we can perform a "natural experiment" by calculating social security wealth both under the pre-reform rules and under

\footnotetext{
${ }^{5}$ Expected replacement rates are not shown for brevity. They are available upon requests from the authors
} 
the post-reform rules, so that each individual has a "counterfactual" level of social security wealth. Since we do not observe the entire working history of the workers, we need to impute future years and past years where necessary. This is done by estimating fixed-effects models for the age earnings profiles ${ }^{6}$. It should be noted that while this allows us to make out-of-the sample extrapolations of the earnings profile, we do not impute any value to gaps within the sample.

Figure 6 below displays the difference in Social Security Wealth under the old (pre reform) and the new (contributive) regime at different ages. The comparison is carried out by considering individuals entirely under either of the two regimes. This suggests that women aged less than 30 and more than 45 experienced, as a result of the reform, larger declines of social security wealth than men.

Figure 6. Difference in Social Security Wealth across the Two Regimes

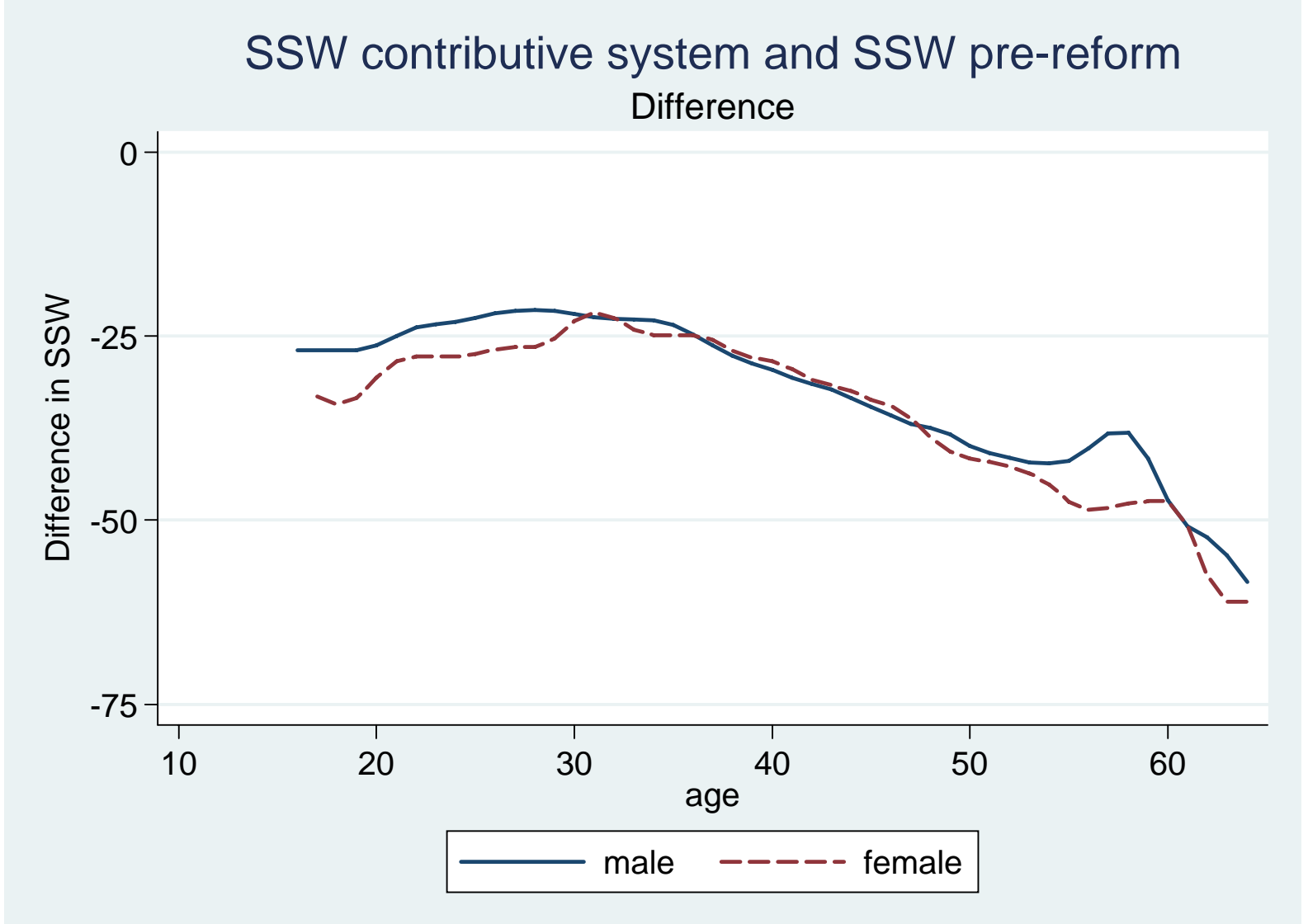

Given this evidence, we can exploit the abrupt change in social security wealth (or peak value) between the pre-reform year 1995 and the post-reform years as determinants of a change in planned retirement decision. It should be noted that the variation in social security wealth (and peak value) between the post-reform years and the year 1995 are entirely due to variations in the legislation and therefore social security wealth (peak value) can be regarded as a valid exogenous variation.

The following regressions are based on the model sketched in (8) and they are run for the sample of workers. They relate the observed change in planned retirement age to a number of

\footnotetext{
${ }^{6}$ Details can be found in Brugiavini-Peracchi 2004.
} 
explanatory variables. These include cohort dummies (cohort 1 is the oldest, individuals born before 1930), gender, education, occupation, seniority and to the "gap years". Furthermore we include our estimate of the difference (DSSP) between the peak value under the new regime and the old regime (year 1995) for any given individual ${ }^{7}$. The use of the Peak Value (rather than SSW) is due to the forward looking nature of the planned retirement age. We run separate regressions for men and women, preserving an identical specification in order to make comparisons. As we make use of both information on years of contributions and planned retirement age, and the only years where these are available in SHIW are 1995, 1998, 2000 and 2002, the sample size is reduced.

In Tables 8 and 9 the dependent variable is the revision occurred between two consecutive years of the survey, in the planned retirement age ${ }^{8}$.

Table 8: Regression of the change in planned retirement age

Men

\begin{tabular}{|c|c|c|c|}
\hline & Coef. & Std. Err. & $\mathrm{t}$ \\
\hline Age & $-\odot, 02387$ & 0,027272 & $-0,88$ \\
\hline $\operatorname{coh} 3640$ & $-2,02336$ & 1,250872 & $-1,62$ \\
\hline coh4145 & $-2,49691$ & 1,216308 & $-2,05$ \\
\hline $\operatorname{coh} 4650$ & $-2,90095$ & 1,226569 & $-2,37$ \\
\hline coh5155 & $-3,00994$ & 1, 261795 & $-2,39$ \\
\hline coh5660 & $-3,28504$ & 1,31537 & $-2,50$ \\
\hline coh6165 & $-3,46654$ & 1, 389657 & $-2,49$ \\
\hline $\operatorname{coh} 6670$ & $-4,00148$ & 1,487269 & $-2,69$ \\
\hline $\operatorname{coh} 7175$ & $-3,88177$ & 1,595457 & $-2,43$ \\
\hline $\operatorname{coh} 7680$ & $-3,37265$ & 1,728102 & $-1,95$ \\
\hline Married & 0,118524 & $\odot, 24979$ & 0,47 \\
\hline medium-edu & $\odot, 132152$ & 0,311247 & $\odot, 42$ \\
\hline high-edu & $\odot, 441811$ & $\odot, 4 \odot 2435$ & 1,10 \\
\hline private sector & $-\odot, 15054$ & $\odot, 185953$ & $-0,81$ \\
\hline self-employed & $\odot, 038953$ & $\odot, 246626$ & 0,16 \\
\hline Senior & $\odot, 427109$ & $\odot, 600161$ & $\odot, 71$ \\
\hline Mid & $\odot, 504331$ & $\odot, 511988$ & $\odot, 99$ \\
\hline North & $\odot, 188216$ & $\odot, 207572$ & 0,91 \\
\hline South & $-\odot, 23552$ & 0,221421 & $-1,06$ \\
\hline gap-years & $\odot, 030187$ & 0,021426 & 1,41 \\
\hline DSSP/1000 & $-\odot, 023228$ & $\odot, 002434$ & $-9,54$ \\
\hline _cons & 5,45993 & 2,164341 & 2,52 \\
\hline R-squared: & & & 0,041 \\
\hline Number of obser & ions & & 2750 \\
\hline
\end{tabular}

\footnotetext{
${ }^{7}$ Details of the estimation of social security wealth under the different regimes are provided in Appendix 3

${ }^{8}$ It should be noted that while all changes are based on 2-years intervals, between 1995 and 1998 we have a 3 years interval. This should not affect our results as there should be no "heaping" or piling up in the expectation variable if taken over three years. On the other hand, the Dini reform takes place exactly within that period.
} 


\section{Table 9: Regression of the change in planned retirement age Women}

\begin{tabular}{|c|c|c|c|}
\hline & Coef. & Std. Err. & $t$ \\
\hline Age & $-0,00054$ & 0,035971 & $-0,01$ \\
\hline $\operatorname{coh} 3135$ & $-4,79243$ & 4,641566 & $-1,03$ \\
\hline $\operatorname{coh} 3640$ & $-1,56671$ & 2,343934 & $-\odot, 67$ \\
\hline coh4145 & $-3,05158$ & 2,157497 & $-1,41$ \\
\hline $\operatorname{coh} 4650$ & $-3,31202$ & 2,05219 & $-1,61$ \\
\hline coh5155 & $-2,97688$ & 1,957537 & $-1,52$ \\
\hline coh5660 & $-2,91751$ & 1,883896 & $-1,55$ \\
\hline coh6165 & $-2,32298$ & 1,814788 & $-1,28$ \\
\hline coh6670 & $-3,19252$ & 1,764972 & $-1,81$ \\
\hline $\operatorname{coh} 7175$ & $-1,34957$ & 1,746632 & $-\odot, 77$ \\
\hline married & $\odot, 122168$ & $\odot, 26913$ & 0,45 \\
\hline Medium-edu & $\odot, 664887$ & $\odot, 506712$ & 1,31 \\
\hline high-edu & $\odot, 456547$ & $\odot, 559948$ & 0,82 \\
\hline private sector & $-\odot, 55131$ & $\odot, 247101$ & $-2,23$ \\
\hline Self-employed & $\odot, 479927$ & $\odot, 438906$ & 1,09 \\
\hline Senior & 2,194045 & $\odot, 738252$ & 2,97 \\
\hline Mid & 1,559067 & $\odot, 643821$ & 2,42 \\
\hline North & $\odot, 557459$ & $\odot, 276256$ & 2,02 \\
\hline South & 0,192263 & $\odot, 311676$ & $\odot, 62$ \\
\hline gap-years & $\odot, 057137$ & $\odot, 027851$ & 2,05 \\
\hline $\mathrm{DSSP} / 1000$ & $-0,01469$ & $\odot, 0 \odot 42 \odot 2$ & $-3,5$ \\
\hline _cons & 1,590119 & 1,931871 & $\odot, 82$ \\
\hline juar & 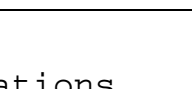 & & 0,0155 \\
\hline
\end{tabular}

The key variables are the gap years and the difference in the social security peak value. Gap years have essentially no effect for men while they have a positive and significant effect for women: a higher number of gap years induces a delay in the planned retirement age, i.e. women revise their expectations planning to work longer. The difference in the peak values is negative and significant for both men and women, but it is larger for men than women. It is also more precisely estimated for men due to the larger sample size. This suggests that a decrease in social security wealth (actually observed) is associated to an increase in the planned retirement age, as we would expect, but that this effect is larger for men, while women are affected in these revisions, unlike men, by gaps in career.

Although the variation in the Peak Value (variable DSSP) is only due to changes in legislation and it is therefore exogenous, one could argue that this variable (Peak Value) is measured with noise, calling for the use of instrumental variables. In Appendix 4 we provide the analogue of Table 8 and Table 9, where the variable DSSP has been instrumented. Albeit less precise, our results are qualitatively similar to those commented above. 


\section{Final Remarks}

The main purpose of this paper was to analyse how pension reforms altered retirement decisions and retirement plans of women and men by exploiting the pension reforms carried out in Italy in the 1990s.

Our results suggest that the effects may not be second order and are broadly in line with what one could expect from economic theory. In particular, the reduced generosity of pension systems would seem to postpone retirement decisions. While men seem to be more reactive than women to changes in pension rules, we found for women a significant and positive effect of gaps in career. The former result has to do with the fact that women have to fill their gap years whatever the pension rules. In other words, it may be the presence of binding constraints related to eligibility which reduces the responsiveness of women to changes in pension rules. The effect of "gap years" is significant for women who plan to work longer the higher the number of gap years.

In future work we plan to investigate the effect of changes in pension regimes on labour supply decisions of men and women over the entire lifetime. In particular, we are interested in evaluating whether these reforms changed decisions as to the timing of entry in the labour market, notably for women, given the fact that the new rules force them to accumulate a longer contribution record. This would also allow us to capture the actual (rather than planned) behaviour of the cohorts who were mostly affected by the reforms. 


\section{References}

Attanasio O.P. e A. Brugiavini (2003), Social security and households' saving, Quarterly Journal of Economics,. vol.118, n.3, pag.1075-1120.

Baxter M. (2001) Social security as a financial asset: gender-specific risks and returns, NBER working paper, 2138, MIT

Blundell, R., J. Ham and C. Meghir (1995), "Unemployment, discouraged workers and female labour supply", manuscript, University of Pittsburgh

Blundell, R., C. Meghir, and S. Smith, (2002) "Pension Incentives and the Pattern of Early Retirement," Economic Journal 112 (March )

Bottazzi, R., T. Jappelli and M. Padula, (2006), Retirement expectations, pension reforms, and their impact on private wealth accumulation," Journal of Public Economics, Elsevier, vol. 90(12), pages $2187-2212$

Brugiavini A. and F. Peracchi (2004), Micro-Modeling of Retirement Behavior in Italy, in: "Social Security Programs and Retirement around the World: Micro-Estimation", J.Gruber e D. A. Wise (eds.), The University of Chicago Press, Chicago, pp. 345-399

Clare, R (2004) Why can't a woman be more like a man - gender differences in retirement savings ASFA (Association Superannutaion Funds of Austrialia) Research Centre.

Disney R. (1996) Can we afford to grow older?, MIT Press

Disney R. (2004), Are contributions to public pension programmes a tax on employment?' Economic Policy, July, 39, 269-311

Eckstein Z. and K. Wolpin (1990), „On the estimation of labor force participation, job search and job matching models using panel data, Chapter 4 in Advances in theory of measurement of unemployment, ed. by Yoram Weiss and Giden Fishelson, New York Macmillan.

Gruber, J. and D. Wise, (1999) Social Security Programs and Retirement around the World, Chicago University Press for the NBER.

Gruber, J. and D. Wise, (2004) "Social Security Programs and Retirement around the World: Micro-Estimation”, J.Gruber e D. A. Wise (eds.), The University of Chicago Press, Chicago

Gruber, J. (1998). "Health Insurance and the Labor Market," NBER Working Papers 6762, National Bureau of Economic Research.

Gustman A. and T. Steinmeier, (1986) "A Structural Retirement Model,” Econometrica 54, 555-584.

Gustman A. and T. Steinmeier (1994) "Employer Provided Health Insurance and Retirement Behavior", Industrial and Labor Relations Review, Vol. 48, No. 1. pp. 124-140.

Gustman A. and T. Steinmeier (1995) Pension Incentives and Job Mobility, . Kalamazoo, Michigan: Upjohn Institute for Employment Research. 
GustmanA. and T. Steinmeier, (2000) "Retirement in Dual-Career Families: A Structural Model," Journal of Labor Economics 18 (July ), 503-545.

Hyslop D. (1999) "State dependence, serial correlation and heterogeneity in intertemporal labor force participation of married women, Econometrica, 67, N.6, 1255-1294.

E. Lazear, "Why Is There Mandatory Retirement?" JPE, 1979, Vo. 87, N. 6, pp. 1261-1284.

A. Lindbeck \& M. Persson (2003), "The Gains from Pension Reform", Journal of Economic Literature, Vol. 41, No.1.

C. Olivetti, (2006). "Changes in Women's Hours of Market Work: The Role of Returns to Experience," Review of Economic Dynamics, vol. 9(4), pages 557-587, October. 


\section{Appendix 1}

The changes in pension regimes

Table A1: Key Features of the Pension Regimes in Italy

\begin{tabular}{|c|c|c|c|}
\hline & Pre-1993 regime & 1992 reform & 1995 reform \\
\hline Normal retirement age & $\begin{array}{c}60(\text { men }) \\
55(\text { women })\end{array}$ & $\begin{array}{c}65 \text { (men) } \\
60(\text { women })\end{array}$ & $\begin{array}{l}\text { Any age after } 56 \text { (for } \\
\text { both men and women) }\end{array}$ \\
\hline Transitional period & & Until about 2032 & Until about 2035 \\
\hline Pensionable earnings & $\begin{array}{c}\text { Average of last } 5 \text { years } \\
\text { real earnings } \\
\text { (converted to real } \\
\text { values through price } \\
\text { index) }\end{array}$ & $\begin{array}{l}\text { Career average } \\
\text { earnings (converted to } \\
\text { real values through } \\
\text { price index }+1 \%)\end{array}$ & $\begin{array}{l}\text { Career contributions } \\
\text { (capitalized using a 5- } \\
\text { year moving average of } \\
\text { GDP growth rate) }\end{array}$ \\
\hline Pension benefit & $\begin{array}{c}2 \% *(\text { pensionable } \\
\text { earnings }) *(t), \\
\text { where } t \text { is years of tax } \\
\text { payments (at most } 40)\end{array}$ & $\begin{array}{c}2 \% *(\text { pensionable } \\
\text { earnings }) *(t), \\
\text { where } t \text { is years of tax } \\
\text { payments (at most } 40)\end{array}$ & $\begin{array}{c}\text { Proportional to } \\
\text { capitalized value of } \\
\text { career contributions, } \\
\text { the proportionality } \\
\text { factor increasing with } \\
\text { age at retirement (from } \\
.04720 \text { at age } 57 \text { to } \\
.06136 \text { at age } 65 \text { ) }\end{array}$ \\
\hline Pension indexation & $\begin{array}{l}\text { Cost of living plus real } \\
\text { earnings growth }\end{array}$ & Cost of living & Cost of living \\
\hline Pension to survivor & $\begin{array}{c}60 \% \text { to spouse } \\
20 \% \text { to each child } \\
40 \% \text { to each child (if } \\
\text { no spouse) }\end{array}$ & Same & Same \\
\hline $\begin{array}{l}\text { Years of contributions } \\
\text { for eligibility }\end{array}$ & 15 & 20 & 5 \\
\hline $\begin{array}{c}\text { Early retirement } \\
\text { provision }\end{array}$ & $\begin{array}{l}\text { Any age if contributed } \\
\text { to SS for } 35 \text { years or } \\
\text { more, no actuarial } \\
\text { adjustment }\end{array}$ & $\begin{array}{l}\text { Any age if contributed } \\
\text { to SS for } 35 \text { years or } \\
\text { more, no actuarial } \\
\text { adjustment }\end{array}$ & $\begin{array}{l}\text { No early retirement } \\
\text { provision }\end{array}$ \\
\hline Total Payroll tax & $\begin{array}{c}24.5 \% \text { of gross } \\
\text { earnings }\end{array}$ & $\begin{array}{c}27.17 \% \text { of gross } \\
\text { earnings }\end{array}$ & $\begin{array}{l}32.7 \% \text { of gross } \\
\text { earnings }\end{array}$ \\
\hline
\end{tabular}




\section{Appendix 2}

\section{The SHIW data}

The Survey of Household Income and Wealth - SHIW is conducted, since 1978, every other year and has been widely used by several researchers to analyze the saving behaviour of Italian households. ${ }^{9}$ For a detailed analysis of the features of the sample see Brandolini and Cannari (1995).

The survey contains detailed information on household income, consumption and wealth, as well as a number of demographic and economic variables. The data are generally of excellent quality and have been used for a variety of different studies. ${ }^{10}$ Since 1989 , the survey also contains a (relatively small) longitudinal component.

The main advantage of the Survey for our study is the fact that it was conducted immediately before and immediately after the reforms of the pension system.

In this paper we focus in waves from 1989 to 2002:

* contribution years are recorded only from 1995 to 2002;

* replacement rates are recorded in 1989 in 1991 in 2000 and 2002;

* year of entry into labour market and planned retirement age are in all relevant waves;

The sample size of workers and retirees only is as follows:

Men:

\begin{tabular}{|c|c|c|c|c|c|c|}
\hline$\stackrel{\text { I }}{\text { Activity I }}$ & 1991 & $\begin{array}{l}\text { year } \\
1995\end{array}$ & 1998 & 2000 & 2002 | & Total \\
\hline $\begin{array}{l}\text { worker I } \\
\text { retired | }\end{array}$ & $\begin{array}{l}5,748 \\
2,127\end{array}$ & $\begin{array}{l}5,169 \\
2,283\end{array}$ & $\begin{array}{l}4,555 \\
1,960\end{array}$ & $\begin{array}{l}4,952 \\
2,386\end{array}$ & $\begin{array}{l}4,532 \mid \\
2,537 \mid\end{array}$ & $\begin{array}{l}24,956 \\
11,293\end{array}$ \\
\hline Total | & 7,875 & 7,452 & 6,515 & 7,338 & 7,069 | & 36,249 \\
\hline
\end{tabular}

Women:

\begin{tabular}{|c|c|c|c|c|c|c|}
\hline Activity | & 1991 & 1995 & 1998 & 2000 & $2002 \mid$ & Total \\
\hline $\begin{array}{l}\text { work } \\
\text { retir }\end{array}$ & $\begin{array}{c}3,050 \\
1,540\end{array}$ & & & & & $\begin{array}{l}14,82 \\
7,715\end{array}$ \\
\hline & 4,590 & 4,728 & 4,051 & 4,487 & 4,681 | & 22,537 \\
\hline
\end{tabular}

\footnotetext{
${ }^{9}$ See, for instance, the volume edited by Ando, Guiso and Visco (1995) and the studies cited therein. As explained below in this Appendix, we also make use of the Bank of Italy Surveys for the years 1978, 1979, 1980, 1981, 1982, 1983, 1984 and 1986. These samples have a slightly different format from the surveys available in subsequent years, however they contain enough information to estimate age-earnings profiles.

${ }^{10}$ Of particular interest, because of their originality, are the modules on households expectations and on cash balances. In what follows we use the data on planned retirement age.
} 
Workers distinguished by sector of activity.

Men:

$\begin{array}{ccccccc}\begin{array}{c}\text { Sector of | } \\ \text { activity | }\end{array} & 1991 & \begin{array}{r}\text { year } \\ 1995\end{array} & 1998 & 2000 & 2002 \text { | } & \text { Total } \\ \begin{array}{c}\text { private employees | } \\ \text { public employees | }\end{array} & 1,982 & 2,610 & 2,361 & 2,698 & 2,494 \mid & 13,145 \\ \text { self-employed | } & 1,259 & 1,148 & 979 & 959 & 884 \mid & 5,477 \\ & 1,411 & 1,215 & 1,295 & 1,154 \mid & 6,334\end{array}$

\begin{tabular}{llllll|l} 
Total | & 5,748 & 5,169 & 4,555 & 4,952 & 4,532 & 24,956
\end{tabular}

Women:

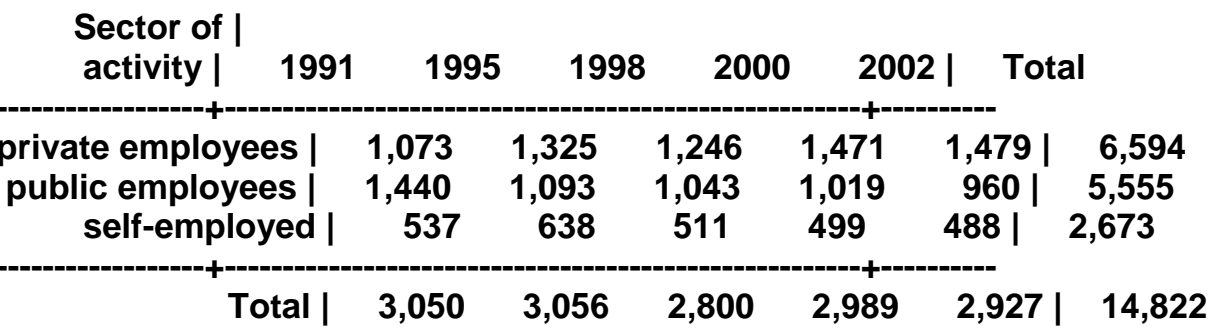

Finally the rotating panel is as follows

\begin{tabular}{|l|r|}
\hline Years & Sample size \\
\hline $1993-1995$ & 3268 \\
\hline $1995-1998$ & 2275 \\
\hline $1998-2000$ & 3269 \\
\hline $2000-2002$ & 3008 \\
\hline
\end{tabular}




\section{Appendix 3 Estimating Social Security}

Estimation of social security wealth at micro level requires essentially two ingredients: the age-earnings profile and the rules for benefit computation and eligibility. Both are especially important in Italy, as the process of social security reform involves moving from a "final salary" type of benefit formula (pre-1993 system) to a lifetime earnings formula (1992 reform) and to a formula based on the value of lifetime contributions (1995 reform). The information available in order to model age-earnings profiles in the SHIW sample consists of age, gender, education, occupation, sector of employment and region of working activity. However we only make use of gender, age and occupation in order to model these profiles, given the reduced sample size (see also Attanasio and Brugiavini, 2003).

Given the period in which the individual is observed (this ranges from a minimum of one wave to a maximum of 5 waves in our data) the estimation of the age earnings profile is used for both backward projections and forward projections in earnings.

As in Brugiavini and Peracchi (2004), individual real age-earnings profiles are assumed to be completely flat after the last year of observed earnings, if this occurs above age 50 . This corresponds to the assumption that, at the individual level, the real earnings process is a random walk with no drift. The "jump-off" point for the earnings projections is taken to be the last year of observed earnings. This jump-off point pins down the level of the ageearnings profile for each individual, while age effects are assumed essentially constant within gender groups. Note that this might underestimate future earnings growth, particularly for younger cohorts, but we have no alternative.

The actual calculation of SSW is "a rolling" present discounted value of a stream of future benefits, taking account of mortality. For each additional year of work SSW has to be recomputed. We assume a real discount factor of 1.5 percent. Benefits are defined in real terms and the indexation rules prevailing under each legislation are implemented (e.g. before the 1995 reform, for senior workers, we apply the defined benefit system). We also assume that real earnings growth after 2002 the last year of the SHIW sample), is constant at $1.5 \%$. We carry out calculations as follows.

We assume that workers are single, though we know marital status. In the Italian legislation, the only major difference between a single worker and a married worker is eligibility to survivors' pension and we assume that this does not substantially alter the SSW profile. We assume variation in mortality only by sex and age.

We apply the prevailing legislation to impute eligibility rules, and benefits become available only when eligibility requirements are met. For workers in the "mixed system" eligibility is based on the pre-1995 regime. Eligibility for "minimum benefits" are also applied. 


\section{Appendix 4}

Instrumental Variables Estimates of the difference in planned retirement age Men

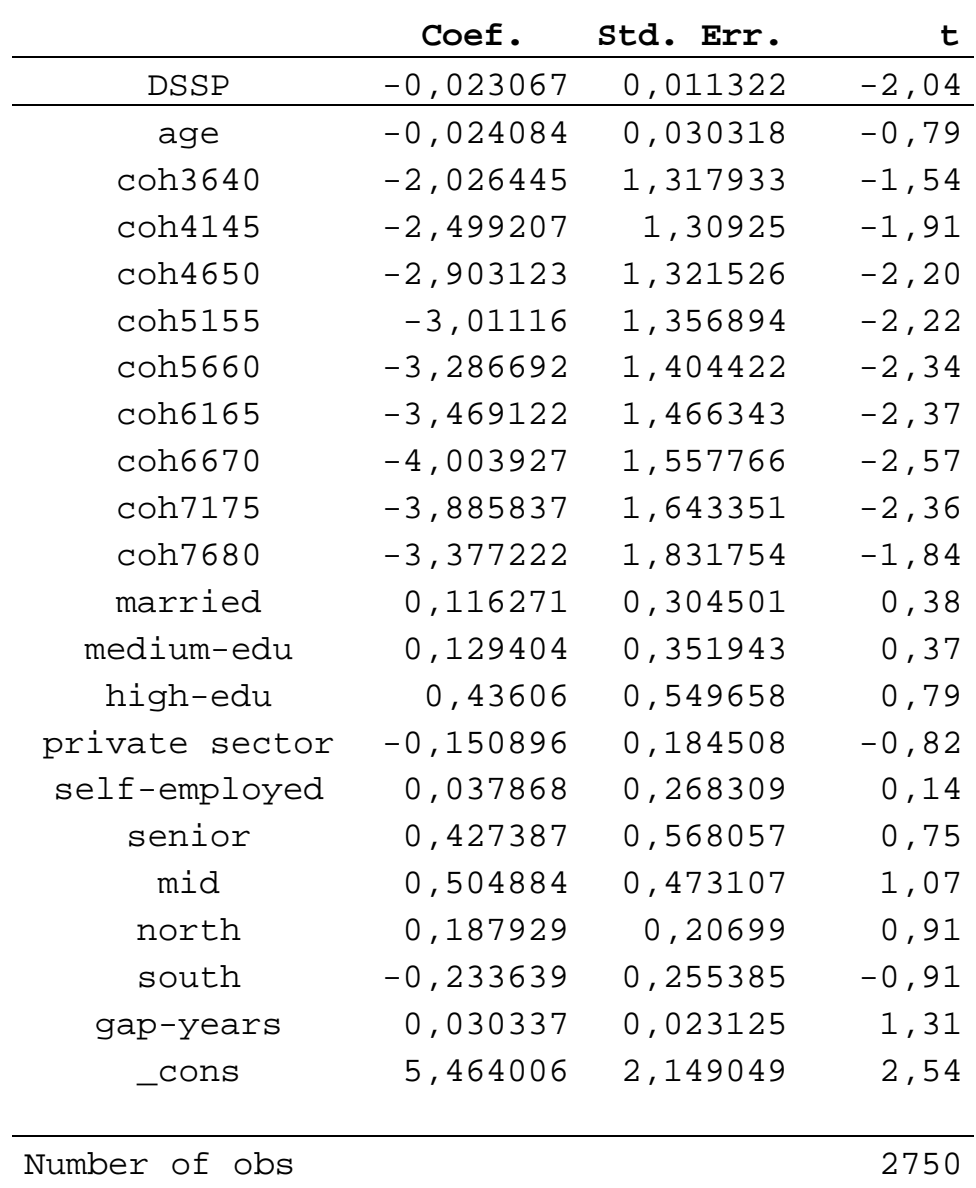


Instrumental Variables Estimates of the difference in planned retirement age Women

\begin{tabular}{|c|c|c|c|}
\hline & Coef. & Std. Err. & $\mathrm{t}$ \\
\hline DSSP & $-\odot, 016194$ & $\odot, 015995$ & $-1,01$ \\
\hline age & 0,001405 & 0,041195 & $\odot, 03$ \\
\hline $\operatorname{coh} 3640$ & 3,306315 & 1,247844 & 2,65 \\
\hline coh4145 & 1,822954 & 1,10258 & 1,65 \\
\hline $\operatorname{coh} 4650$ & 1,562535 & 1,142522 & 1,37 \\
\hline coh5155 & 1,901828 & 1,21468 & 1,57 \\
\hline $\operatorname{coh} 5660$ & 1,963693 & 1,326331 & 1,48 \\
\hline coh6165 & 2,569572 & $1,5 \odot 4923$ & 1,71 \\
\hline $\operatorname{coh} 6670$ & 1,721119 & 1,810457 & $\odot, 95$ \\
\hline $\operatorname{coh} 7175$ & 3,571842 & 1,958745 & 1,82 \\
\hline $\operatorname{coh} 7680$ & 4,939266 & 2,925819 & 1,69 \\
\hline married & $\odot, 126722$ & $\odot, 274675$ & 0,46 \\
\hline medium-edu & $\odot, 682841$ & $\odot, 5402$ & 1,26 \\
\hline high-edu & 0,485765 & $\odot, 64957$ & 0,75 \\
\hline private sector & $-\Theta, 555405$ & $\odot, 251497$ & $-2,21$ \\
\hline self-employed & $\odot, 506985$ & $\odot, 557843$ & $\odot, 91$ \\
\hline senior & 2,214249 & $\odot, 753401$ & 2,94 \\
\hline mid & 1,562262 & 0,636632 & 2,45 \\
\hline north & $\odot, 566265$ & $\odot, 286915$ & 1,97 \\
\hline south & $\odot, 189109$ & 0,3084 & 0,61 \\
\hline gap-years & $\odot, 057003$ & $\odot, 025669$ & 2,22 \\
\hline _cons & $-3,315035$ & 2,817518 & $-1,18$ \\
\hline ( & & & 1498 \\
\hline
\end{tabular}

